\title{
Placental DNA methylation in caesarean sections - a pilot study
}

\author{
Aneta Słabuszewska-Jóźwiak ${ }^{1}$, Marta Włodarczyk ${ }^{2}$, Michał Ciebiera ${ }^{3}$, Joanna Zwolińska4 \\ Cezary Wojtyła ${ }^{4}$, Grażyna Nowicka ${ }^{2}$, Grzegorz Jakiel ${ }^{1}$, Dorota Raczkiewicz ${ }^{5}$
}

\author{
${ }^{1}$ First Department of Obstetrics and Gynaecology, Centre of Postgraduate \\ Medical Education, Warsaw, Poland \\ ${ }^{2}$ Department of Biochemistry and Pharmacogenomics, Faculty of Pharmacy, \\ Medical University of Warsaw, Warsaw, Poland \\ ${ }^{3}$ Second Department of Obstetrics and Gynaecology, Centre of Postgraduate \\ Medical Education, Warsaw, Poland \\ ${ }^{4}$ Department of Obstetrics and Gynaecology, W. Orlowski Teaching Hospital \\ of Warsaw, Warsaw, Poland \\ ${ }^{5}$ Institute of Statistics and Demography, Collegium of Economic Analysis, \\ SGH Warsaw School of Economics, Warsaw, Poland
}

Submitted: 22 January 2020

Accepted: 8 April 2020

Arch Med Sci

DOI: https://doi.org/10.5114/aoms.2020.95422

Copyright @ 2020 Termedia \& Banach

\begin{abstract}
Introduction: Caesarean section (CS) is the most common medical procedure performed in women all over the world. There is a hypothesis that caesarean section changes DNA methylation, and it has been linked to immune-mediated diseases such as diabetes in late infant health outcomes. The aim of the study was to evaluate the relationship between caesarean section and DNA methylation patterning in the placenta by measurement of global DNA methylation.

Material and methods: We included in the study 111 healthy, pregnant women in singular pregnancy at term of delivery (gestational age at least 37 weeks). The study involved global methylation in placental tissue from 46 pregnant women, delivered by vaginal route, and 49 pregnant women, delivered by elective caesarean section (ECS) before the start of labour. In 16 of the elective caesarean section cases, regular uterine contractions were declared. An ELISA-based kit was used for an assessment of the global DNA methylation.

Results: Global DNA methylation in the placenta in elective caesarean sections (3.02 on average) was significantly lower compared to intrapartum caesarean sections (3.71 on average) and vaginal deliveries (3.64 on average), but did not significantly differ between intrapartum caesarean sections and vaginal deliveries. Global DNA methylation in the placenta in male newborns was significantly higher (4.86 on average) than in female newborns (3.31 on average) in vaginal deliveries but not in either elective or intrapartum caesarean sections.

Conclusions: Caesarean sections performed without uterine contractions significantly influenced global DNA methylation in the placenta. Moreover, a sexual dimorphism at the level of placental global DNA methylation was demonstrated. Further studies investigating different panels of genes may help to identify genes with aberrant methylation in newborn infants delivered by caesarean section compared to vaginal delivery, as well as demonstrate sexual dimorphism.
\end{abstract}

Key words: DNA methylation, pregnancy, placenta, caesarean section.

\author{
Corresponding author: \\ Aneta Stabuszewska-Jóźwiak \\ $\mathrm{MD}, \mathrm{PhD}$ \\ First Department \\ of Obstetrics \\ and Gynaecology \\ Centre of Postgraduate \\ Medical Education \\ 90 Żelazna St \\ 01-004 Warsaw, Poland \\ Phone: +48 504 187-297 \\ E-mail: anetaslabuszewska@ \\ gmail.com
}




\section{Introduction}

Caesarean section (CS) is the most common interventional procedure performed in women all over the world. Although caesarean section can be a life-saving intervention for mothers and children, it can also lead to short-term and long-term health consequences.

The placenta is the interface between maternal and foetal circulations, integrating maternal and foetal signals to selectively regulate nutrient, gas, and waste exchange, as well as secrete hormones. In turn, the placenta helps create an in utero environment and controls foetal growth and development. The placenta differentiates from the extraembryonic trophectoderm, giving rise to villous cytotrophoblasts that can proliferate or fuse to form the multinuclear syncytiotrophoblast layer that acts as the barrier between the maternal and foetal circulations, and to extra-villous trophoblasts, which infiltrate the decidua and remodel the maternal spiral arteries [1]. This differentiation involves changes in gene expression mediated by distinct epigenetic alterations. By the blastocyst stage, the genome is almost completely hypomethylated; however, the imprinted epigenetic marks remain intact during this stage. At the blastocyst stage, the inner cell mass and trophectoderm undergo a wave of de novo DNA methylation but to different extents, resulting in differences in final global DNA methylation levels [2, 3].

Evidence suggests that the placental epigenome plays key roles in healthy foetal development, and all situations leading to changes in its global methylation may limit its functions $[4,5]$. There is a hypothesis that a caesarean section changes the placental DNA methylation and has been linked to late infant health outcomes $[6,7]$. Epidemiological and clinical studies have shown that children delivered by caesarean section are associated with a higher risk of developing illnesses such as asthma [8], respiratory disorders [9], and an increased risk of diseases associated with immune function [10]. However, a meta-analysis only identified an increased risk of obesity up to the age of 5 years, and asthma up to the age of 12 years in children born by caesarean section [11]. The elective caesarean section may increase the risk of child asthma due to exposure to different microbiota during delivery [12].

Epigenetics mechanisms, often defined as regulating gene activity independently of underlying DNA sequence, have been implicated in the development of many human diseases, including cancers [13], neurological disorders [14], type 2 diabetes [15], and hypertension [16]. The most studied epigenetic mechanism is DNA methylation, which involves the addition of a methyl group to a cytosine, usually in the context of cytosine-phos- pho-guanine dinucleotides (CpG site). DNA methylation is commonly associated with gene silencing and contributes to $\mathrm{X}$-chromosomal inactivation, genomic imprinting, and transcriptional regulation of tissue-specific genes during cellular differentiation [17]. CpG sites often cluster together in CpG islands close to the promoter and regulatory regions of genes, and within this context increased DNA methylation blocks access to the underlying DNA sequence, leading to reduced gene expression [18]. Although CpG methylation status is conferred early in development and is relatively stable [19], it can change due to environmental exposure and lifestyle factors, e.g smoking [20, 21], chronic stress [22], or maternal disease [23]. The majority of these factors have been shown to affect both global and gene-specific placental methylation [24]. Moreover, uteroplacental insufficiency, the most common cause of foetal growth restriction, induces epigenetics modifications in placental cardiometabolic genes in which differential methylation may confer increased risk of cardiologic and metabolic disease in adulthood [25].

None of the placenta studies explores in detail the association between the mode of delivery, uterine contractions, and DNA methylation modification. Some hypotheses describe surges of stress hormones during labour that advance the development of essential pathways to enable the infant to survive outside the womb, thus implicating changes in the genome in response to stress. However, these changes may not occur if the infant does not undergo such stress, such as during a caesarean section.

In this study, we set out to characterise the relationship between caesarean section and DNA methylation patterning in the placenta. The measurement of global DNA methylation patterns is a practical means of identifying differential epigenetic effects in neonates. However, the measurement of global methylation cannot rule out differences on the single gene level. This is a pilot study, and in the future we are going to select a panel of genes responsible for obesity and immunomodulation. Moreover, we are going to finish the neonatal follow-up, and the results will be published.

\section{Material and methods}

The study was conducted in 2014-2017 at the delivery units of the First Department of Obstetrics and Gynaecology, Centre of Postgraduate Medical Education in Warsaw, and comprised 111 Caucasian pregnant women who were recruited consequently and fulfilled inclusion criteria for the study.

Prior to delivery, the pregnant women were requested to complete a questionnaire and were asked for permission to collect placental samples 
after detachment for research purposes. The participants were asked to provide information about their date of birth, race, height, pre-pregnancy weight, gestational weight gain, gestational age, parity, pre-existing and existing diseases, infectious diseases, use of antibiotics, and smoking, drug, and alcohol consumption. The inclusion criteria for the study were as follows: maternal age of at least 18 years, singular pregnancy, term delivery (gestational age at least 37 weeks), and newborn weight of at least $2500 \mathrm{~g}$. The exclusion criteria from the study were: multiple gestation, maternal disorders such as preeclampsia, hypertension, diabetes, or gestational diabetes mellitus (GDM), asthma, smoking and drinking alcohol during pregnancy, illicit drugs, infectious diseases, renal disease, allergy, cognitive disorders, use of antibiotics, and premature rupture of membranes.

The foetal and newborn exclusion criteria from the study were as follows: intrauterine grown restriction, Apgar score less than 7 at $1^{\text {st }}$ and $5^{\text {th }}$ min, (Neonatal Intensive Care Unit (NICU) admission, malformations, or chromosomal disorders. Moreover, none of the pregnancies resulted from assisted reproductive technology. Deliveries with labour induction were not included in this study.

The study involved global methylation in placental tissue from 49 pregnant women, delivered by elective caesarean section (ECS) before the start of labour. In 16 cases, elective caesarean section regular uterine contractions were declared. This group was termed the intrapartum caesarean section group (ICS). Indications for all the CS included: previous CS, breech position, or pelvic disproportion. None of the caesarean sections were performed on the grounds of foetal distress and prolonged labour. A reference group was formed, consisting of 46 healthy pregnant women delivering by vaginal route (VD).

Spinal analgesia was applied in all cases in the elective and intrapartum caesarean section group. Women who underwent general analgesia were excluded from the study. In the vaginal delivery group, women with regular and painful uterine constrictions were offered epidural analgesia.

Full-thickness placental tissue samples were collected within $45 \mathrm{~min}$ of birth. All biopsies were performed by aseptic technique. A triangular segment of the placenta was cut near the cord insertion site. The DNA methylation levels were quantified using a 5-mC DNA ELISA kit.

This study was approved by the Centre of Postgraduate Medical Education Ethics Committee number 8/PB/2014.

\section{Global DNA methylation assay.}

Full-thickness placental tissue was collected immediately after spontaneous, non-assisted de- livery. Each placenta was sectioned transversally $(1 \mathrm{~cm})$ using a sterile scalpel near the cord insertion site. The placental sample was washed in sterile $1 \times$ phosphate-buffered saline (PBS, $\mathrm{pH} 7.5$ ) to remove any residual blood and was immediately frozen in liquid nitrogen and stored at $-80^{\circ} \mathrm{C}$ for DNA analysis. The Extract Me DNA Tissue kit (Blirt S.A., Poland) was used for DNA extraction and purification from the placenta. Qubit 2.0 (Thermo Fisher Scientific) was used to determine the DNA yield. Global DNA methylation was isolated from the placental tissue using the 5-mC DNA ELISA kit (Zymo Research, Irvine, CA, USA), according to the manufacturer's instructions. Briefly, $100 \mathrm{ng}$ of DNA was diluted with 5-mC coating buffer and incubated at $98^{\circ} \mathrm{C}$ for $5 \mathrm{~min}$. After denaturation, the DNA was transferred to the plate and incubated at $37^{\circ} \mathrm{C}$ for $1 \mathrm{~h}$. The samples were incubated with capture and detection antibodies, and absorbance was read at $450 \mathrm{~nm}$. A quantification of global DNA methylation was obtained by calculating the amount of methylated cytosine $(5-\mathrm{mC})$ in the sample relative to global cytidine $(5 \mathrm{mC}+\mathrm{dC})$ in the standard curve of a positive control that had been methylated previously. All samples were analysed in duplicate. The mean value per sample was used for further calculations.

\section{Statistical analysis}

The data were statistically analysed using Statistica 13 software. The minimum and maximum values, and the median and interquartile range (lower (25\%) and upper (75\%) quartiles) were estimated for continuous variables, as well as absolute numbers $(n)$ and percentages (\%) of the occurrence of items for categorical variables. The statistical tests were used as follows: Kruskal-Wallis's $\mathrm{H}$ test - to compare continuous variables between three modes of birth; $\chi^{2}$ test - to compare categorical variables between three modes of birth; Mann-Whitney's $U$ test - to compare global DNA methylation between two modes of birth in pairs, between male and female newborns, as well as between epidural analgesia and no analgesia in vaginal deliveries; and Spearman's r correlation coefficient - to correlate global DNA methylation with continuous characteristics. A significance level of 0.05 was assumed throughout the study.

\section{Results}

The maternal and gestational age, parity, pre-pregnancy and pregnancy body mass index (BMI), weight gain during pregnancy, newborn weight, height and gender, and Apgar score both at 1 and 5 min did not differ significantly between the elective and intrapartum caesarean sections and the vaginal delivery groups (Table I). 
Table I. Clinical characteristics of the study group

\begin{tabular}{|c|c|c|c|c|c|c|}
\hline Characteristics & IU & Parameter & $\begin{array}{l}\text { Elective caesarean } \\
\text { section }(N=49)\end{array}$ & $\begin{array}{c}\text { Intrapartum } \\
\text { caesarean section } \\
(N=16)\end{array}$ & $\begin{array}{l}\text { Vaginal delivery } \\
\qquad(N=46)\end{array}$ & $P$-value $\#$ \\
\hline \multirow[t]{2}{*}{ Maternal age } & years & Me (25-75\%) & $32(30-36)$ & $30(28-36)$ & $30(28-33)$ & 0.085 \\
\hline & & Min.-max. & $19-43$ & $25-41$ & $24-40$ & \\
\hline \multirow{2}{*}{$\begin{array}{l}\text { Gestational } \\
\text { age [weeks] }\end{array}$} & $37-38$ & $n(\%)$ & $13(26.53)$ & $5(31.25)$ & $11(23.91)$ & 0.844 \\
\hline & $39-41$ & $n(\%)$ & $36(73.47)$ & $11(68.75)$ & 35 (76.09) & \\
\hline \multirow[t]{4}{*}{ Parity } & 1 & $n(\%)$ & $22(44.90)$ & $13(81.25)$ & $28(60.87)$ & 0.122 \\
\hline & 2 & $n(\%)$ & $25(51.02)$ & $3(18.75)$ & $14(30.43)$ & \\
\hline & 3 & $n(\%)$ & $2(4.08)$ & $0(0.00)$ & $3(6.52)$ & \\
\hline & 4 & $n(\%)$ & $0(0.00)$ & $0(0.00)$ & $1(2.17)$ & \\
\hline \multirow[t]{2}{*}{$\begin{array}{l}\text { Pre-pregnancy } \\
\text { BMI }\end{array}$} & $\mathrm{kg} / \mathrm{m}^{2}$ & Me (25-75\%) & $\begin{array}{c}24.21 \\
(21.51-26.70)\end{array}$ & $\begin{array}{c}21.62 \\
(19.47-25.06)\end{array}$ & $\begin{array}{c}22.75 \\
(20.70-24.91)\end{array}$ & 0.092 \\
\hline & & Min.-max. & $16.41-32.95$ & $17.01-35.16$ & $17.36-30.82$ & \\
\hline \multirow[t]{2}{*}{ Pregnancy BMI } & $\mathrm{kg} / \mathrm{m}^{2}$ & Me (25-75\%) & $\begin{array}{c}29.14 \\
(27.28-30.80)\end{array}$ & $\begin{array}{c}27.42 \\
(25.71-31.71)\end{array}$ & $\begin{array}{c}28.26 \\
(25.82-30.45)\end{array}$ & 0.297 \\
\hline & & Min.-max. & $21.63-38.97$ & $22.55-42.19$ & $20.83-34.93$ & \\
\hline \multirow{4}{*}{$\begin{array}{l}\text { Weight } \\
\text { gain during } \\
\text { pregnancy }\end{array}$} & $\mathrm{kg}$ & Me (25-75\%) & $14(11-18)$ & 17 (14-19) & $14(11-17)$ & 0.494 \\
\hline & & Min.-max. & $2-24$ & $2-25$ & $6-24$ & \\
\hline & $\%$ & Me (25-75\%) & $\begin{array}{c}21.67 \\
(15.15-27.59)\end{array}$ & $\begin{array}{c}30.20 \\
(19.09-33.91)\end{array}$ & $\begin{array}{c}22.02 \\
(16.92-28.57)\end{array}$ & 0.203 \\
\hline & & Min.-max. & $3.08-40.00$ & $2.63-36.36$ & $8.96-42.86$ & \\
\hline \multirow{2}{*}{$\begin{array}{l}\text { Newborn } \\
\text { weight }\end{array}$} & $\mathrm{kg}$ & Me (25-75\%) & $3.50(3.32-3.85)$ & $3.62(3.41-3.80)$ & $3.51(3.12-3.85)$ & 0.476 \\
\hline & & Min.-max. & $2.50-4.60$ & $3.18-4.03$ & $2.66-4.30$ & \\
\hline \multirow{2}{*}{$\begin{array}{l}\text { Newborn } \\
\text { height }\end{array}$} & $\mathrm{cm}$ & Me $(25-75 \%)$ & $54(53-57)$ & $56(53-57)$ & $54(53-56)$ & 0.918 \\
\hline & & Min.-max. & $48-62$ & $50-58$ & $50-60$ & \\
\hline \multirow{2}{*}{$\begin{array}{l}\text { Newborn } \\
\text { gender }\end{array}$} & Male & $n(\%)$ & $21(42.86)$ & $10(62.50)$ & $20(43.48)$ & 0.356 \\
\hline & Female & $n(\%)$ & $28(57.14)$ & $6(37.50)$ & $26(56.52)$ & \\
\hline \multirow{4}{*}{$\begin{array}{l}\text { Apgar score at } \\
1 \text { minute }\end{array}$} & 7 & $n(\%)$ & $0(0.00)$ & $0(0.00)$ & $1(2.17)$ & 0.065 \\
\hline & 8 & $n(\%)$ & $6(12.24)$ & $1(6.25)$ & $0(0.00)$ & \\
\hline & 9 & $n(\%)$ & $11(22.45)$ & $2(12.50)$ & $4(8.70)$ & \\
\hline & 10 & $n(\%)$ & $32(65.31)$ & $13(81.25)$ & $41(89.13)$ & \\
\hline \multirow{4}{*}{$\begin{array}{l}\text { Apgar score at } \\
5 \text { minutes }\end{array}$} & 7 & $n(\%)$ & $0(0.00)$ & $0(0.00)$ & $1(2.17)$ & 0.188 \\
\hline & 8 & $n(\%)$ & $1(2.04)$ & $0(0.00)$ & $0(0.00)$ & \\
\hline & 9 & $n(\%)$ & $8(16.33)$ & $0(0.00)$ & $2(4.35)$ & \\
\hline & 10 & $n(\%)$ & $40(81.63)$ & $16(100.00)$ & $43(93.48)$ & \\
\hline \multirow{2}{*}{$\begin{array}{l}\text { Duration } \\
\text { of uterine } \\
\text { contractions }\end{array}$} & $\mathrm{h}$ & Me (25-75\%) & - & - & $5.46(3.50-7.67)$ & - \\
\hline & & Min.-max. & - & - & $1.17-12.12$ & \\
\hline Analgesia* & Yes & $n(\%)$ & $49(100.00)$ & $16(100.00)$ & 31 (67.39) & - \\
\hline
\end{tabular}

$B M I$ - body mass index. "Kruskal-Wallis $\mathrm{H}$ test or $\chi^{2}$ test were used to compare continuous or categorical variables, respectively, between 3 modes of birth. *Spinal for caesarean section or epidural for vaginal delivery. 


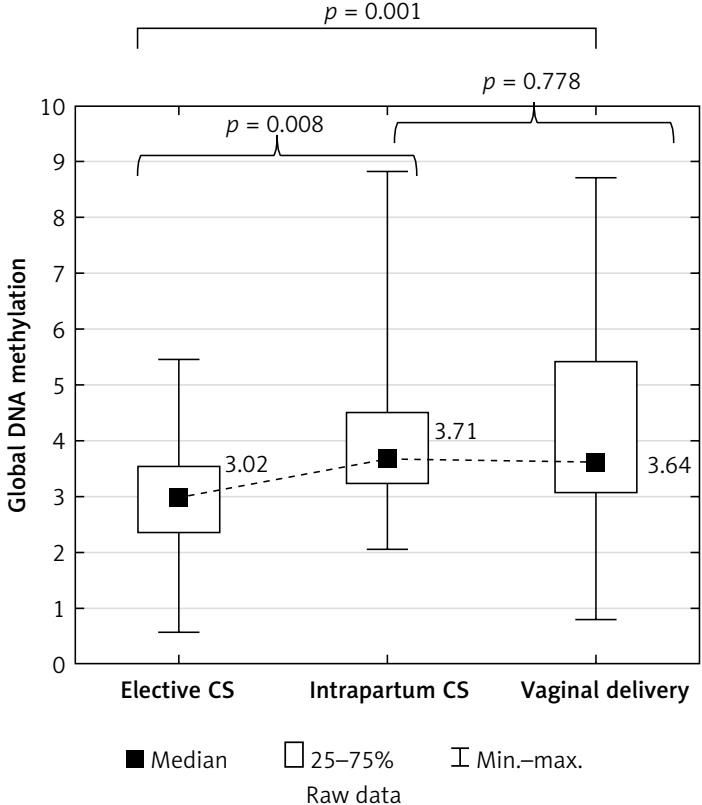

Figure 1. Global DNA methylation in placenta according to mode of birth

The uterine contraction lasted from 1 to 12 $\mathrm{h}$ in vaginal deliveries ( $5.5 \mathrm{~h}$ on average). Spinal analgesia was administered in all the women delivering by caesarean sections, and epidural analgesia in $67 \%$ of the vaginal deliveries. In the elective caesarean sections, global DNA methylation in the placenta was significantly lower (3.02 on average) compared to the intrapartum caesarean sections (3.71 on average, $p=0.008$ ), and in re-

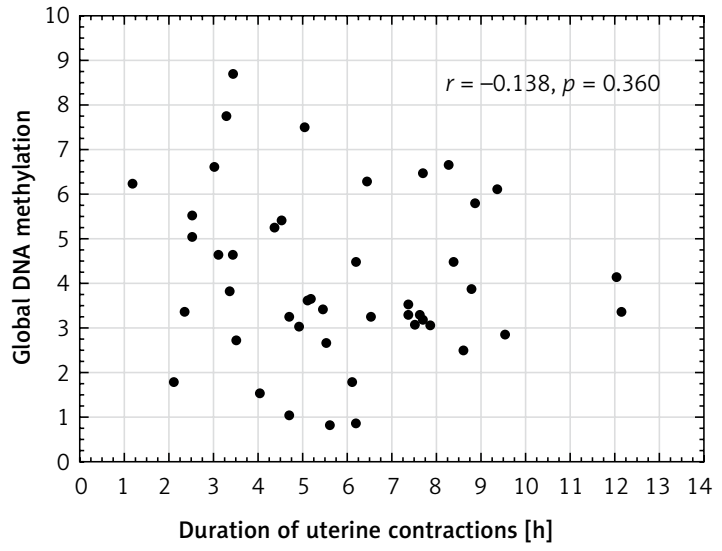

Figure 2. Scatter plot between global DNA methylation in placenta and duration of uterine contractions in vaginal deliveries $(n=46)$

lation to the vaginal deliveries (3.64 on average, $p=0.001)$.

Placental global DNA methylation did not significantly differ between the intrapartum caesarean sections and the vaginal deliveries $(p=0.778$; Figure 1).

No correlation was found between global DNA methylation in the placenta and the duration of uterine contractions in the vaginal deliveries $(r=$ $-0.138, p=0.360$; Figure 2). Placental global DNA methylation did not correlate with the maternal and gestational age, parity, pre-pregnancy and pregnancy BMI, weight gain during pregnancy, newborn weight and height, or with the Apgar score both at 1 and $5 \mathrm{~min}$ in all mode of birth groups (Table II).

Table II. Correlations between placental global DNA methylation and maternal and offspring outcomes

\begin{tabular}{|lccccccccc|}
\hline Characteristics & IU & Test* & \multicolumn{2}{c}{$\begin{array}{c}\text { Elective caesarean } \\
\text { section }(N=49)\end{array}$} & $\begin{array}{c}\text { Intrapartum caesare- } \\
\text { an section }(N=16)\end{array}$ & $\begin{array}{c}\text { Vaginal delivery } \\
(N=46)\end{array}$ \\
\cline { 5 - 10 } & & & & Estimate & $P$-value & Estimate & $P$-value & Estimate & $P$-value \\
\hline Maternal age & Years & $r$ & 0.099 & 0.498 & 0.204 & 0.449 & -0.055 & 0.716 \\
\hline Gestational age & Weeks & $Z$ & 1.880 & 0.060 & 0.680 & 0.497 & 1.622 & 0.105 \\
\hline Parity & Number & $r$ & 0.064 & 0.664 & -0.122 & 0.654 & 0.064 & 0.671 \\
\hline Pre-pregnancy BMI & $\mathrm{kg} / \mathrm{m}^{2}$ & $r$ & -0.048 & 0.744 & -0.358 & 0.174 & -0.161 & 0.284 \\
\hline Pregnancy BMl & $\mathrm{kg} / \mathrm{m}^{2}$ & $r$ & -0.113 & 0.438 & -0.469 & 0.067 & -0.274 & 0.066 \\
\hline $\begin{array}{l}\text { Weight gain during } \\
\text { pregnancy }\end{array}$ & $\mathrm{kg}$ & $r$ & 0.029 & 0.844 & -0.403 & 0.121 & -0.210 & 0.161 \\
\cline { 2 - 9 } & $\%$ & $r$ & 0.004 & 0.979 & -0.099 & 0.716 & -0.096 & 0.526 \\
\hline Newborn weight & $\mathrm{kg}$ & $r$ & -0.044 & 0.764 & -0.490 & 0.054 & -0.037 & 0.805 \\
\hline Newborn height & $\mathrm{cm}$ & $r$ & -0.190 & 0.191 & -0.042 & 0.877 & 0.231 & 0.122 \\
\hline Newborn gender & Male vs. female & $Z$ & 0.354 & 0.724 & 1.356 & 0.175 & 2.294 & 0.022 \\
\hline Apgar at 1 min & Score & $r$ & 0.014 & 0.923 & -0.357 & 0.175 & 0.046 & 0.760 \\
\hline Apgar at 5 min & Score & $r$ & -0.072 & 0.624 & $\#$ & & 0.032 & 0.831 \\
\hline Analgesia & Epidural vs. none & $Z$ & - & - & - & - & 1.640 & 0.101 \\
\hline
\end{tabular}

BMI - body mass index, $r$ - Spearman's correlation coefficient, $Z$ - Mann-Whitney U test. " All newborns delivered by intrapartum caesarean section had the same Apgar score at $5 \mathrm{~min}$ as at $10 \mathrm{~min}$. 


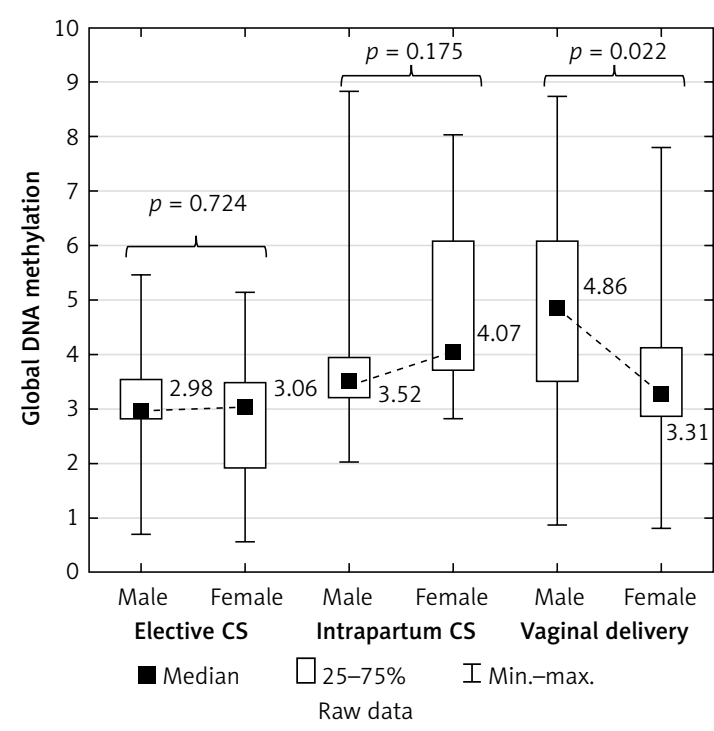

Figure 3. Global DNA methylation in placenta according to gender and mode of birth

Global DNA methylation in the placenta in the male newborns was significantly higher (4.86 on average) than in the female newborns (3.31 on average) in the vaginal deliveries $(p=0.022)$ but not in either the elective or the intrapartum caesarean sections ( $p=0.724$ and $p=0.175$, respectively) (Figure 3).

Placental global DNA methylation did not significantly differ between women with spinal analgesia and women with epidural analgesia $(p=0.154)$.

\section{Discussion}

Placental tissue is not homogenous in terms of methylation values. Although it globally shows hypomethylation, there are some domains of low methylation (large partially methylated domains (PMDs)), which are surrounded by domains of high methylation (highly methylated domains (HMDs)). Interestingly, in PMDs there are smaller islands characterised by hypermethylation of promoter $\mathrm{CpG}$, but the global methylation for this domain still shows aggregate hypomethylation [26]. Genes in PMDs are mostly silenced, which guarantees the specific function of a given tissue. Similar hypomethylation islands are visible in neoplasms [27], for example in breast cancer [13]. Many environmental and lifestyle factors have now been linked to a disrupted DNA methylation profile in the placenta. Smoking [20, 21], alcohol consumption [28], plastic exposure [29], maternal chronic stress [22], maternal diabetes [23], and maternal pre-pregnancy obesity [30], for example, have been shown to affect both global and gene-specific placental methylation.

The placenta is a uniquely suited organ for the study of how genetics (foetal cells) and environment (e.g. maternal health and nutrient provision) interact, and it may provide considerable insights into the developmental programming of disease. The differences in DNA methylation between individuals born by caesarean section and by vaginal delivery represent an interesting hypothesis yet to be fully investigated. A select panel of different methylated gens via caesarean section could be used as a potential test to diagnose placental disorders or to predict foetal outcomes.

In our study, the global DNA methylation levels in the placenta in the elective caesarean sections were significantly lower compared to the vaginal delivery group $(p=0.001)$. However, the placental global DNA methylation levels did not significantly differ between the intrapartum caesarean sections and the vaginal deliveries $(p=0.778)$. Viriani et al. also observed a significantly lower methylation in elective caesarean sections but not in emergency caesarean sections, compared with vaginal deliveries [31]. Franz et al. detected global DNA methylation in umbilical cord blood and did not observe a significant difference in global DNA methylation depending on the mode of delivery, but they showed significantly higher methylation of single genes in newborn infants delivered by elective caesarean section [32]. Some studies have shown that stem cells from infants delivered by caesarean section were globally more methylated than DNA from infants delivered vaginally [33]. The different methods used in these studies have made it difficult to interpret the results of global methylation.

Our study shows significantly higher global DNA methylation in the intrapartum caesarean section group compared to the emergency caesarean section group $(p=0.008)$. This means that uterine constrictions increase placental global DNA methylation; however, the duration of uterine contractions did not correlate with global methylation $(r=-0.138, p=0.360)$. It may be concluded from the obtained results that the stress associated with delivery may be necessary to complete the methylation process occurring in the placenta during pregnancy, and a caesarean section eliminates this key part. It also may cause both hypoand hypermethylation of loci of specific genes and explain the hypothesis of the long-term impact of a caesarean section.

This study represents a pilot study, and hence one limitation is that the number of intrapartum caesarean sections is relatively small (16 participants); nevertheless, the biological significance of the observed phenomenon remains an open question.

DNA methylation is an important regulator of gene function. Foetal sex determination is associated with the risk of several specific pregnancy complications related to placental function. Male 
foetuses have more severe placental histopathological lesions [34] and a higher placental production of endotoxin-induced tumour necrosis factor response than female foetuses [35]. However, the association between foetal sex and placental DNA methylation remains poorly understood. We emphasise the contrast between global DNA methylation and newborn genders. Placental global DNA methylation was significantly higher (4.86 on average) in the male newborns than in the female newborns (3.31 on average) in vaginal deliveries ( $p=0.022$ ), but not in either the elective or the intrapartum caesarean sections $(p=0.724$ and $p=0.175$ ). Further investigations will be continued to explain this phenomenon. Martin et al. [36] demonstrated sexual dimorphism at the level of the human placental DNA methylation and hypothesised that epigenetic dimorphism could result in the sex-dependent transport of toxicants, nutrients, and signalling molecules across the placenta. These differences could have consequences for both early- and later-life health outcomes, e.g. hypertension has to been diagnosed more often among men but not women [16].

Many studies have investigated the maternal impact on molecular and functional changes between male and female foetuses. In pre-eclampsia, significant changes were found only in placentas from female foetuses [37]. Sex differences were observed in DNA methylation associated with the summative maternal socioeconomic status score, in which placentas derived from female pregnancies showed more robust differential CpG methylation than placentas from male pregnancies. Moreover, maternal socioeconomic status adversity was associated with the differential methylation of genes with a key role in gene transcription and placental function, potentially altering immunity and stress response [38], but none of the studies have investigated uterine constriction and sex differences in DNA methylation.

In conclusion, a caesarean section performed without uterine contractions significantly influences global DNA methylation in the placenta. In the obtained results, methylation is lower than in vaginal deliveries, and the significance of the differences is not impaired by other factors. Furthermore, this study demonstrates sexual dimorphism at the level of placental global DNA methylation. Further studies investigating different panels of genes may help to identify genes with aberrant methylation in newborn infant delivery by caesarean section compared to vaginal delivery, and could help to demonstrate sexual dimorphism.

\section{Acknowledgments}

All authors qualified for authorship by contributing substantially to this work and developing the original concept of this study collectively. All authors contributed to the critical discussion, reviewed the final version of the manuscript, and approved it for publication.

\section{Conflict of interest}

The authors declare no conflict of interest.

\section{References}

1. Cartwright JE, Fraser R, Leslie R, Wallace AE, James JL. Remodeling at the maternal - fetal interface: relevance to human pregnancy disorders. Reproduction 2010; 140: 803-13.

2. Hajkova P. Epigenetic reprogramming - taking a lesson from the embryo. Curr Opin Cell Biol 2010; 22: 342-50.

3. Hajkova P, Jeffries SJ, Lee C, Miller N, Jackson SP, Surani MA. Genome-wide reprogramming in the mouse germ line entails the base excision repair pathway. Science 2010; 329: 78-82.

4. Bianco-Miotto T, Mayne BT, Buckberry S, Breen J, Rodriguez Lopez CM, Roberts CT. Recent progress towards understanding the role of DNA methylation in human placental development. Reproduction 2016; 152: 23-30.

5. Vlahos A, Mansell T, Saffery R, Novakovic B. Human placental methylome in the interplay of adverse placental health, environmental exposure, and pregnancy outcome. PLoS Genet 2019; 15: e1008236.

6. Almgren M, Schlinzig T, Gomez-Cabrero D, et al. Cesarean delivery and hematopoietic stem cell epigenetics in the newborn infant: implications for future health? Am J Obstet Gynecol 2014; 211: e1-7.

7. Dahlen HG, Kennedy HP, Anderson CM, et al. The EPIIC hypothesis: intrapartum effects on the neonatal epigenome and consequent health outcomes. Med Hypotheses 2013; 80: 656-62.

8. Chu S, Zhang Y, Jiang Y, et al. Cesarean section without medical indication and risks of childhood allergic disorder, attenuated by breastfeeding. Sci Rep 2017; 7: 9762.

9. Hansen AK, Wisborg K, Uldbjerg N, Henriksen TB. Risk of respiratory morbidity in term infants delivered by elective caesarean section: cohort study. BMJ 2008; 336: 85-7.

10. Kristensen K, Henriksen L. Cesarean section and disease associated with immune function. J Allergy Clin Immunol 2016; 37: 587-90.

11. Keag OE, Norman JE, Stock SJ. Long-term risks and benefits associated with cesarean delivery for mother, baby, and subsequent pregnancies: systematic review and meta-analysis. PLoS Med 2018; 15: e1002494.

12. Dominguez-Bello MG, Costello EK, Contreras M, et al. Delivery mode shapes the acquisition and structure of the initial microbiota across multiple body habitats in newborns. Proc Natl Acad Sci USA 2010; 107: 11971-5.

13. Hon GC. Hawkins RD, Caballero OL, et al. Global DNA hypomethylation coupled to repressive chromatin domain formation and gene silencing in breast cancer. Genome Res 2012; 22: 246-58.

14. Babenko O, Kovalchuk I, Metz G. Epigenetic programming of neurodegenerative diseases by an adverse environment. Brain Research 2012; 1444: 96-111.

15. Kim M. DNA methylation: a cause and consequence of type 2 diabetes. Genom Inform 2019; 17: e38.

16. van Abeelen AF, de Rooij SR, Osmond C, et al. The sex-specific effects of famine on the association be- 
tween placental size and later hypertension. Placenta 2011; 32: 694-8

17. Boland MJ, Nazor KL, Loring JF. Epigenetic regulation of pluripotency and differentiation. Circ Res 2014; 115: 311-24.

18. Jones PA. Functions of DNA methylation: islands, start sites, gene bodies and beyond. Nat Rev Genet 2012; 13 484-92.

19. Nelissen ECM, van Montfoort APA, Dumoulin JCM Evers JLH. Epigenetics and the placenta. Human Reproduct Update 2011; 17: 397-417.

20. Morales E, Vilahur N, Salas LA, et al. Genome-wide DNA methylation study in human placenta identifies novel loci associated with maternal smoking during pregnancy. Int J Epidemiol 2016; 45: 1644-55.

21. Fa S, Larsen TV, Bilde K, et al. Assessment of global DNA methylation in the first trimester fetal tissues exposed to maternal cigarette smoking. Clin Epigenetics 2016; 8: 128.

22. Brunst KJ, Tignor N, Just A, et al. Cumulative lifetime maternal stress and epigenome-wide placental DNA methylation in the PRISM cohort. Epigenetics 2018; 13: 665-81.

23. Alexander J, Teague AM, Chen J, et al. Offspring sex impacts DNA methylation and gene expression in placentae from women with diabetes during pregnancy. PLoS One 2018; 13: e0190698.

24. Wilson SL, Leavey K, Cox BJ, Robinson WP. Mining DNA methylation alterations towards a classification of placental pathologies. Hum Mol Genet 2018; 27: 135-46.

25. Chen PY, Chu A, Liao WW, et al. Prenatal growth patterns and birthweight are associated with differential DNA methylation and gene expression of cardiometabolic risk genes in human placentas: a discovery-based approach. Reprod Sci 2018; 25: 523-39.

26. Schroeder DI, Blair JD, Lott P, et al. The human placenta methylome. Proc Natl Acad Sci USA 2013; 110: 6037-42.

27. Sobieszkoda D, Czech J, Gablo N, et al. MGMT promoter methylation as a potential prognostic marker for acute leukemia. Arch Med Sci 2017; 13: 1433-41.

28. Loke YJ, Muggli E, Nguyen L, et al. Time- and sex-dependent associations between prenatal alcohol exposure and placental global DNA methylation. Epigenomics 2018; 10: 981-91.

29. Basak S, Srinivas V, Duttaroy AK. Bisphenol-A impairs cellular function and alters DNA methylation of stress pathway genes in first trimester trophoblast cells. Reprod Toxicol 2018; 82: 72-9.

30. Binder NK, Beard SA, Kaitu'u-Lino TJ, Tong S, Hannan NJ, Gardner DK. Paternal obesity in a rodent model affects placental gene expression in a sex-specific manner. Reproduction 2015; 149: 435-44.

31. Virani S, Dolinoy DC, Halubai S, et al. Delivery type not associated with global methylation at birth. Clin Epigenetics 2012; 4: 8 .

32. Franz MB, Poterauer $M$, Elhenicky $M$, et al. Global and single gene DNA methylation in umbilical cord blood cells after elective caesarean: a pilot study. Eur J Obstet Gynecol Reprod Biol 2014; 179: 121-4.

33. Malin A, Schlinzig T, Gomez-Cabrero D, et al. Cesarean delivery and hematopoietic stem cell epigenetics in the newborn infant: implications for future health? Am J Obstet Gynecol 2014; 211: 502.e1-8.

34. Ghidini A, Salafia CM. Histologic placental lesions in women with recurrent preterm delivery. Acta Obstet Gynecol Scand 2005; 84: 547-50.
35. Yeganegi M, Watson CS, Martins A, et al. Effect of Lactobacillus Rhamnosus GR-1 supernatant and fetal sex on lipopolysaccharide-induced cytokine and prostaglandin-regulating enzymes in human placental trophoblast cells: implications for treatment of bacterial vaginosis and prevention of preterm labor. Am J Obstet Gynecol 2008; 200: 532.e1-8.

36. Martin E, Smeester L, Bommarito PA, et al. Sexual epigenetic dimorphism in the human placenta: implications for susceptibility during the prenatal period. Epigenomics 2017; 9: 267-78.

37. Chu T, Bunce K, Shaw P, et al. Comprehensive analysis of preeclampsia-associated DNA methylation in the placenta. PLoS One 2014; 9: e107318.

38. Santos HP, Bhattacharya A, Martin EM, et al. Epigenome-wide DNA methylation in placentas from preterm infants: association with maternal socioeconomic status. Epigenetics 2019; 14: 751-65. 